Jurnal Sains Peternakan Nusantara

\title{
RESPON PALATABILITAS FODDER PADI (ORYZA SATIVA) HIDROPONIK SEBAGAI PAKAN TERNAK SAPI PO KEBUMEN
}

\author{
Panji Prasetyo ${ }^{\text {a }}$, Dwi Wahyono ${ }^{\text {b }}$, Adi Fathul Qohar ${ }^{\mathrm{c}}$, dan Nunur Nuraeni ${ }^{\mathrm{d}}$ \\ a,b,c,d Program Studi Peternakan, Universitas Ma'arif Nahdlatul Ulama Kebumen, Kebumen
}

panjhintz@gmail.com

\begin{abstract}
ABSTRAK
Penelitian ini bertujuan untuk mengetahui respon palatabilitas fodder padi hidroponik sebagai pakan ternak sapi PO Kebumen. Penelitian dilaksanakan di kelompok tani ternak (KTT) sumber rejeki, Kecamatan Klirong, Kabupaten Kebumen pada tanggal 1 Januari sampai 28 Febuari 2021. Rancangan penelitian adalah rancangan acak lengkap dengan pola searah, dengan menggunakan 4 perlakuan yang diulang sebanyak 4 kali sehigga terdapat 16 satuan percobaan. Perlakuan terdiri dari P0 (penambahan POC 0 gram/ 2L air), P1 (penambahan POC 30 gram/2L air), P2 (penambahan POC 60 gram/2L air), P3 (penambahan POC 90 $\mathrm{gram} / 2 \mathrm{~L}$ air). Variabel respon palatabilitas yang diukur meliputi waktu merenggut (detik), jumlah konsumsi (gram) dan waktu konsumsi (menit). Data yang diperoleh dilakukan analisis variansi (ANOVA), apabila perlakuan berpengaruh nyata akan dilanjutkan uji BNJ. Hasil penelitian menunjukan bahwa perlakuan penambahan POC pada fodder padi yang diberikan pada ternak sapi PO Kebumen tidak berpengaruh nyata $(\mathrm{P}>0.05)$ terhadap respon palatabilitas. Rataan waktu merenggut pakan 10,50-14,75 detik, sedangkan waktu konsumsi sebesar 15 menit setiap 300 gram pakan yang diberikan. Respon palatabilitas fodder padi terbaik pada penambahan POC 60 gram/2L air.
\end{abstract}

Kata kunci: palatabilitas, fodder, sapi PO Kebumen

\begin{abstract}
This study aims to determine the palatability response of hydroponic rice fodder as animal feed for PO Kebumen cattle. The study was carried out in the Sumber Rejeki livestock farmer group, Klirong District, Kebumen Regency on January 1 to February 28, 2021. The research design was a completely randomized design with a unidirectional pattern, using 4 treatments which were repeated 4 times. The treatments consisted of $P O$ (addition of POC 0 gram $/ 2 L$ of water), $P 1$ (addition of $P O C 30 \mathrm{grams} / 2 L$ of water), P2 (addition of POC $60 \mathrm{grams} / 2 L$ of water), P3 (addition of POC 90 grams/2L of water). The palatability response variables that were measured included the taking time (seconds) and consumption time (minutes). The data obtained was analyzed for variance (ANOVA), if it had an effect on the $B N J$ trial. The results showed that the treatment of adding POC to animal feed given to PO Kebumen cattle had no significant effect $(p>0.05)$ on the palatability response. The average time to take feed is 10.50-14.75 seconds, while the consumption time is 15 minutes for every 300 grams of feed given. The best palatability response of rice fodder was at the addition of $90 \mathrm{gram} / 2 \mathrm{~L} P O C$ of water.
\end{abstract}


Jurnal Sains Peternakan Nusantara

Keywords: palatability, fodder, PO Kebumen cattle

\section{PENDAHULUAN}

Keberhasilan suatu usaha peternakan ruminansia ditentukan pada pakan itu sendiri. Pakan merupakan hal penting dalam pencapaian target produksi ternak ruminansia (Toe et al., 2016). Pakan digunakan oleh ternak untuk hidup pokok, produksi dan reproduksi (Suyitman, 2014; Suyitman et al., 2003). Hijauan pakan merupakan sumber bahan pakan yang berasal dari tanaman atau tumbuhan. Hijauan pakan menjadi pondasi awal dalam pengadaan peternakan ruminansia sebagai penentuan tingkat produksi ternak (Hendarto, 2005; Adi Fathul Qohar et al., 2019). Pengadaan hijauan pakan harus memperhatikan aspek kualitas, kuantitas serta kontinyuitas guna meningkatkan produktivitas ternak (Qohar et al., 2020; Sari et al., 2016). Indonesia merupakan negara dengan iklim tropis yang mana terdapat musim kemarau dan musim hujan. Ketersediaan pakan sepanjang tahun akan berpengaruh terhadap produktivitas ternak yang berimbas pada keuntungan usaha peternakan (Saputro et al., 2018). Pada musim kemarau ketersediaan hijauan akan berkurang dibandingkan dengan musim hujan (Adi Fathul Qohar et al., 2019, 2021). Disisi lainnya ketersediaan lahan untuk menanam hijauan pakan semakin berkurang dikarenakan proses peralihan lahan. Ketersedian hijauan pakan yang berkurang diperlukan hijauan alternatif yakni fodder hidroponik.

Hidroponik secara harfiah berati hydro $=$ air, dan phonic $=$ pengerjaan. Secara umum hidroponik adalah sistem budidaya pertanian tanpa menggunakan tanah, akan tetapi menggunakan air yang berisi larutan nutrient mix (Roidah, 2014). Hidroponik yang biasanya dibudidayakan di dalam rumah kaca (grennhouse) untuk menjaga supaya pertumbuhan dan perkembangan tanaman berjalan secara optimal dan terlindungi dari faktor luar(Saputro et al., 2018). Berbagai jenis hidroponik dapat dibedakan dari media yang digunakan untuk berdiri tegaknya tanaman (Suhardiyanto, 2011). Media tersebut biasanya bebas dari unsur hara (steril), sementara itu, pasokan unsur hara akan dialirkan melalui pipa atau disiramkan secara manual (Roidah, 2014). Media tanam hidroponik tersebut dapat berupa kerikil, pasr, gabus, arang, zeolite atau tanpa media agregat (hanya air saja). Menggunakan media tanam tersebut yang paling terpenting adalah harus bersih dari hama sehingga tidak menumbuhkan jamur atau penyakit lainnya yang ditimbulkan. Fodder hidroponik merupakan hasil dari sistem pertanian tanpa menggunakan media tanah melainkan menggunakan media air yang berisi larutan nutrient (Rayani et al., 2021). Berbagai jenis biji yang digunakan untuk fodder hidroponik adalah padi (Oryza sativa). Biji padi mudah digunakan dan didapatkan oleh peternak.

Penggunaan fodder padi hidroponik digunakan untuk ternak ruminansia seperti sapi, domba dan kambing untuk pertumbuhan dan perkembangan hidup ternak. Fodder padi memiliki potensi yang cukup tinggi dalam meningkatkan respon palatabilitas ternak sapi PO Kebumen. Tujuan penelitian ini adalah untuk mengetahui respon 
Jurnal Sains Peternakan Nusantara

palatabilitas fodder padi (Oryza sativa) sistem hidroponik sebagai pakan ternak sapi PO Kebumen.

\section{METODOLOGI PENELITIAN}

Lokasi penelitian dilaksanakan di Kelompok Tani Ternak (KTT) Sumber Rejeki, Kecamatan Klirong, Kabupaten Kebumen, pada tanggal 1 Januari sampai 28 Februari 2021. Materi penelitian yang digunakan adalah sebanyak $2,4 \mathrm{~kg}$ fodder padi yang dilakukan dengan sistem hidroponik tanpa menggunakan media tanah akan tetapi menggunakan media air yang diberikan pada 16 ekor sapi PO Kebumen.

Kegiatan penelitian meliputi :

1. Pemilihan biji jagung

Benih awal yang digunakan pada penelitian ini adalah jagung. Benih yang akan ditanam akan diawali dengan uji kemurnian dan uji tumbuh. Uji daya tumbuh dilakukan dengan cara melakukan penanaman sebanyak 60 biji. Benih tersebut akan diuji pada media kertas yang dibasahi air dan kemudian digulung selama kurang lebih 5 hari. Setelah uji benih dilakukan, maka akan dilakukan pemilihan benih kemudian dilakukan penanaman pada media yang telah disiapkan.

2. Sterilisasi alat dan bahan

Desinfeksi alat bahan dilakukan untuk meminimalisir pertumbuhan jamur. Nampan yang dipakai sebagai wadah penanaman dibersihkan menggunakan detergen sebelum digunakan. Selanjutnya benih yang akan dipakai juga direndam pada larutan hipoklorit dengan kandungan 3\% selama kurang lebih 10 menit.

3. Penanaman

Benih ditanam dengan menggunakan media tanam berupa nampan berkapasitas 300 $\mathrm{g}-500 \mathrm{~g}$ benih. Benih ditanam dengan cara ditebar. Benih yang ditanam tersebut diletakkan pada rak-rak yang telah diatur sedemikian rupa.

4. Pemeliharaan

Kegiatan pemeliharaan yang dilakukan yaitu mengontrol air pada sistem irigasi otomatis yang telah diatur, pengontrolan kondisi lingkungan. Irigasi diatur dengan waktu penyiraman dilakukan setiap 4 jam sekali yaitu pukul 00.00 WIB, $04.00 \mathrm{WIB}$, 08.00 WIB, 12.00 WIB, 16.00 WIB, 20.00 WIB.

5. Pemanenan. Pemanenan fodder padi dilakukan pada umur 21 HST. Pemanenan diambil seluruh tanaman sampai ke akarnya jangan sampai terputus. Setelah fodder diambil kemudian diberikan ke ternak sapi PO Kebumen sebanyak 300 gram sesuai perlakuan yang dicobakan.

Setelah fodder diambil kemudian diberikan ke ternak sapi PO kebumen sebanyak 300 gram sesuai perlakuan yang dicobakan. Rancangan penelitian yang dicobakan adalah rancangan acak lengkap (RAL) pola searah dengan 4 perlakuan dilakukan pengulangan 4 kali sehingga diperoleh 16 unit percobaan. (Steel \& Torrie, 1994) model matematik Rancangan Acak Lengkap sebagai berikut: 


$$
\mathbf{Y}_{\mathbf{i j}}=\mu+\tau_{\mathrm{i}}+\epsilon_{\mathrm{ij}}
$$

Keterangan:

$\mathbf{Y}_{\mathbf{i j}}$ : Nilai hasil dari respon pada es krim dari perlakuan ke-i dan ulangan ke-j

$\boldsymbol{\mu}$ : Nilai tengah respon kecepatan leleh

$\tau_{i}$ : Pengaruh penambahan sari buah bit pada perlakuan ke-i

$\epsilon_{\mathrm{ij}}$ : Pengaruh galat percobaan dari perlakuan ke-i dan ulangan ke-j

i : Banyaknya perlakuan

j : Banyaknya ulangan tiap perlakuan

Adapun perlakuan yang dicobakan sebagai berikut:

$\mathrm{P} 0=$ penambahan $\mathrm{POC} 0$ gram/2liter air

$\mathrm{P} 1=$ penambahan $\mathrm{POC} 30$ gram/2liter air

$\mathrm{P} 2=$ penambahan $\mathrm{POC} 60$ gram/2liter air

P3 = penambahan POC 90 gram/2liter air

Data yang diperoleh dari hasil penelitian dilakukan analisis sidik ragam (ANOVA) menggunakan aplikasi SPSS versi 25. Apabila hasil analisis ragam menunjukan perbedaan nyata $(\mathrm{P}<0.05)$ akan dilakukan uji lanjut yakni dengan uji Beda Nyata Jujur (BNJ). Peubah yang diamati adalah waktu merenggut (detik), jumlah konsumsi (gram) dan waktu konsumsi (menit) pakan.

\section{HASIL DAN PEMBAHASAN}

\section{Waktu Merenggut Fodder Padi Pada Sapi PO Kebumen}

Waktu merenggut merupakan parameter respon palatabilitas ternak ruminansia. Waktu merenggut didefinisikan sebagai waktu yang dibutuhkan oleh ternak pertama kali merenggut pakan dalam satuan detik. Semakin lama ternak merenggut pakannya maka pakan tersebut tidak mempunyai palatabilitas yang bagus, dan sebaliknya bila semakin cepat ternak merenggut pakannya maka pakan tersebut mempunyai palatabilitas yang bagus. 


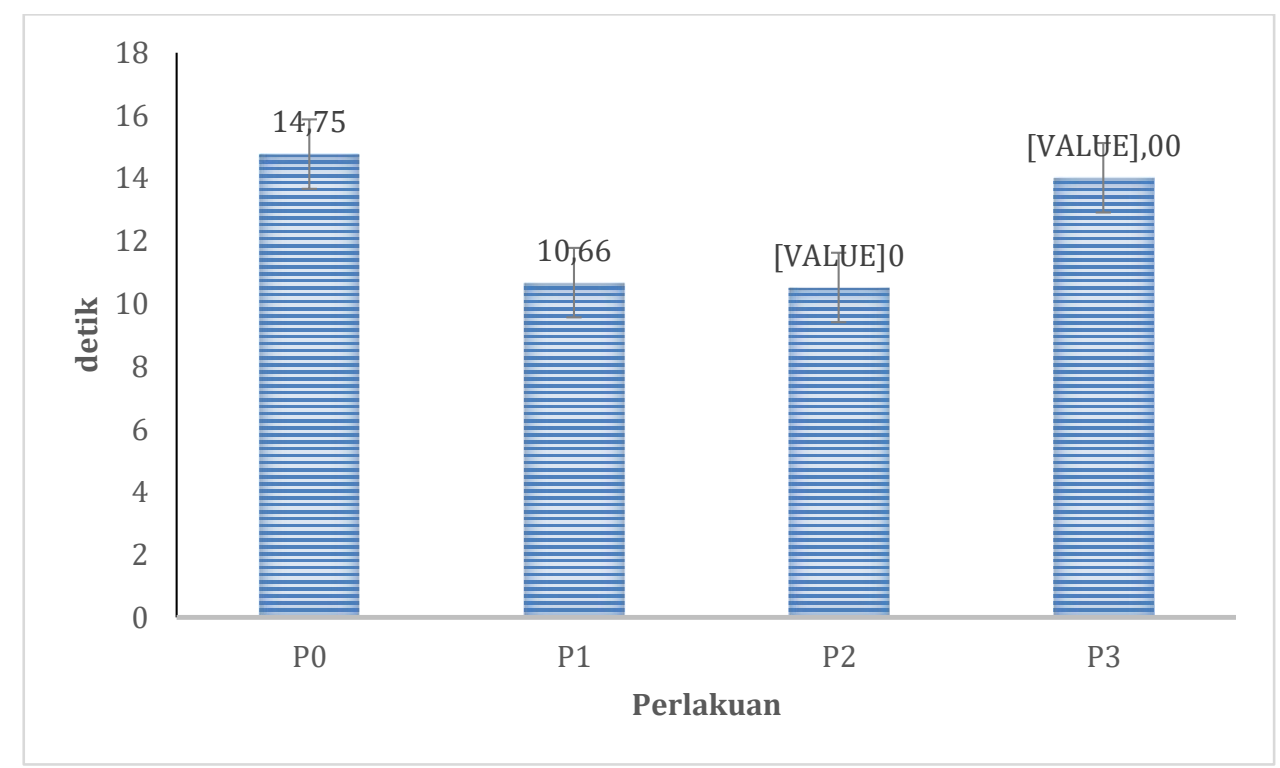

Gambar 1. Rataan waktu merenggut fodder padi oleh sapi PO Kebumen

Hasil penelitian respon palatabilitas fodder padi hidroponik sebagai pakan ternak disajikan pada Gambar 1. Hasil rataan waktu merenggut fodder padi pada penelitian terendah pada perlakuan P2 sebesar 10,5 detik. Sedangkan tertinggi yakni pada perlakuan P0 yakni sebesar 15 detik. Hasil analisis sidik ragam menunjukan bahwa perlakuan penambahan pupuk POC tidak berpengaruh nyata $(\mathrm{P}>0.05)$ terhadap waktu merenggut pakan fodder padi oleh ternak sapi PO Kebumen.

Perlakuan POC tidak berpengaruh dimungkinkan oleh faktor-faktor seperti penampilan fisik pakan, tekstur, warna dan aroma pakan. Hal tersebut dibenarkan oleh Sudarma, (2018) bahwa palatabilitas ternak dipengaruhi oleh penampilan fisik pakan, tekstur, warna dan aroma pakan ternak sebelum sapi tersebut merenggut pakan. Sapi PO merenggut makanannya dengan menggunakan mulutnya. Kegiatan Sapi PO merenggut pakan fodder padi biasanya diikuti proses penciuman ke pakannya. Hal tersebut dimungkinkan karena sapi belum pernah diberikan pakan dalam bentuk fodder padi sehingga sapi mencium pakan terlebih dahulu sebelum pakan direnggut.

\section{Jumlah Konsumsi Fodder Padi Pada Sapi PO Kebumen}

Jumlah konsumsi merupakan parameter uji palatabilitas fodder padi hidroponik. Konsumsi pakan merupakan jumlah pakan jumlah pakan yang dimakan oleh ternak yang akan digunakan untuk mencukupi kebutuhan pokok dan proses produksi. Peningkatan jumlah konsumsi pakan akan meningkatkan nilai nutrisi hijauan pakan yang berkualitas rendah untuk terna ruminansia (Banamtuan et al., 2020; Wahyono \& Sadarman, 2020). Peningkatan jumlah konsumsi akan berakibat pada pasokan kandungan nutrisi pakan yang akan diolah menjadi produk hasil peternakan seperti daging dan susu. Fluktuasi jumlah konsumsi pakan dimungkinkan disebabkan oleh faktor-faktor yakni faktor internal dan eksternal. Nafsu makan merupakan faktor yang 
berpengaruh terhadap jumlah konsumsi fodder jagung hidroponik (Buntoro et al., 2014; Kustyorini et al., 2020; Oyekunle et al., 2018).

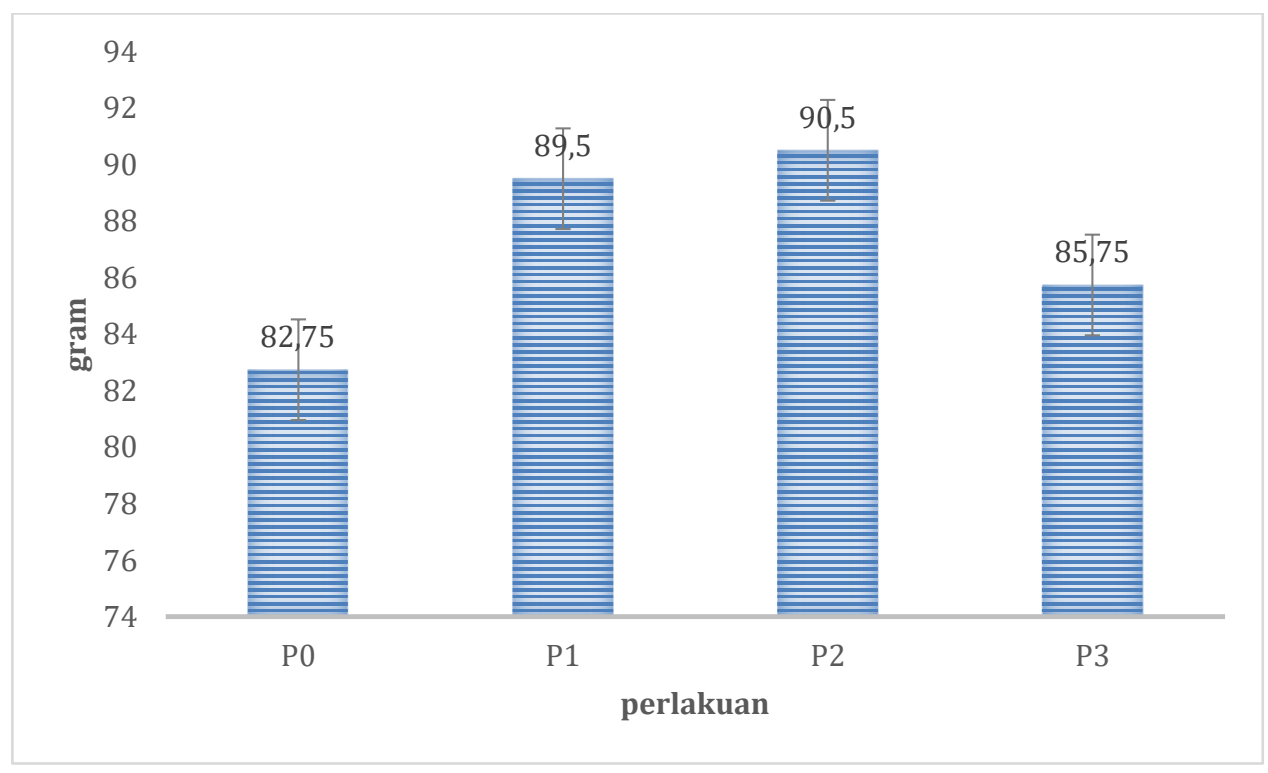

Gambar 2. Rataan jumlah konsumsi fodder padi oleh sapi PO Kebumen

Hasil analisis sidik ragam menunjukan bahwa perlakuan perlakuan penambahan pupuk POC tidak berpengaruh nyata $(\mathrm{P}>0.05)$ terhadap waktu konsumsi pakan fodder padi oleh ternak sapi PO Kebumen. Hal tersebut dikarenakan bahwa pemberian POC pada penanaman fodder jagung hidroponik belum mampu meningkatkan jumlah konsumsi yang berpengaruh terhadap peningkatan jumlah serat. Jumlah konsumsi pakan dipengaruhi oleh palatabilitas, daya cerna, bangsa, jenis kelamin, umur dan kondisi kesehatan ternak (Hafez, 2000; Sudarma, 2018). Palatabilitas fodder padi yang diukur dengan jumlah konsumsi pakan dari penelitian yang dilakukan relatif rendah dikarenakan masih banyak pakan fodder padi yang tersisa.

\section{Waktu Konsumsi Fodder Padi Pada Sapi PO Kebumen}

Waktu konsumsi pakan diartikan sebagai waktu yang dibutuhkan ternak untuk menghabiskan pakan yang diberikan. Waktu konsumsi pakan merupakan parameter palatabilitas yang mana mempengaruhi tingkat kesukaan pakan. Fodder yang baik memiliki waktu konsumsi yang singkat, apabila waktunya terlalu lama maka fodder tersebut memiliki tingkat palatabilitas yang rendah.

Hasil penelitian respon palatabilitas yaitu waktu konsumsi fodder padi yang dikonsumsi oleh sapi PO Kebumen (Gambar 3.). Hasil rataan waktu konsumsi fodder padi memiliki waktu yang sama disemua perlakuan yang dicobakan yakni sebesar 15,00 menit. Hasil analisis sidik ragam bahwa perlakuan penambahan pupuk POC tidak berpengaruh nyata $(\mathrm{P}>0.05)$ terhadap waktu konsumsi pakan fodder padi oleh ternak sapi PO Kebumen. Hal tersebut dimungkinkan karena jumlah yang diberikan hanya 300 gram per perlakuan yang menyebabkan waktu konsumsi pakan fodder tersebut relatif sama. 


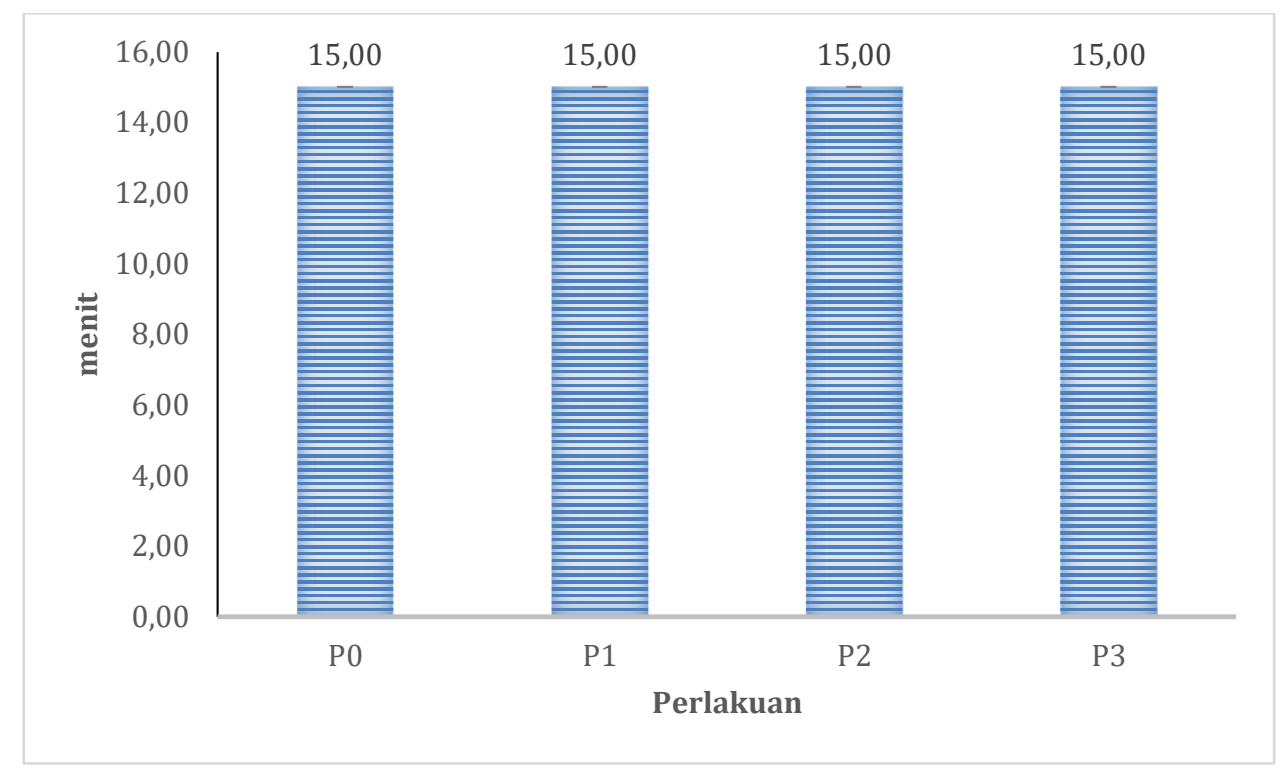

Gambar 3. Rataan waktu konsumsi fodder padi oleh sapi PO Kebumen

Perlakuan POC tidak berpengaruh dimungkinkan oleh faktor-faktor seperti penampilan fisik pakan, tekstur, warna dan aroma pakan. Hal tersebut dibenarkan oleh Sudarma, (2018) bahwa palatabilitas ternak dipengaruhi oleh penampilan fisik pakan, tekstur, warna dan aroma pakan ternak. Sapi akan mengkonsumsi pakan dengan menggunakan mulut juga lidahnya. Tingkat palatabilitas ternak sapi PO Kebumen yang dicobakan memiliki tingkat palatabilitas yang sama.

\section{KESIMPULAN}

Pengaruh POC tidak berpengaruh nyata terhadap waktu merenggut dan waktu konsumsi pakan pada sapi PO Kebumen. Rataan waktu merenggut pakan 10,50-14,75 detik, jumlah konsumsi sebesar 82,75-90,75 gram, sedangkan waktu konsumsi sebesar 15 menit setiap 300 gram pakan yang diberikan.

\section{DAFTAR PUSTAKA}

Banamtuan, S., Jelantik, I. G. N., Lestari, G. A. Y. \& Benu, I. (2020). Pengaruh Substitusi Fodder Jagung Pada Silase Rumput Alam ( Effect of Corn Fodder Substitution for Native Grass Silage on Fiber. Jurnal Nukleus Peternakan, 7(1), 63-74.

Buntoro, B. H., Rogomulyo, R. \& Trisnowati, S. (2014). Pengaruh Takaran Pupuk Kandang dan Intensitas Cahaya Terhadap Pertumbuhan dan Hasil Temu Putih (Curcuma zedoaria L.). Vegetalika, 3(4), 29-39.

Hafez, E. S. E. (2000). Reproduction in Farm Animals (7 th). Kiawah island.

Hendarto, E. (2005). Pengaruh kombinasi pupuk organik dan taraf urea terhadap kualitas visual dan produksi rumput raja (. Jurnal Pembangunan Pedesaan, 
Jurnal Sains Peternakan Nusantara Respon Palatabilitas Fodder Padi (Oryza Sativa) Hidroponik sebagai Pakan Ternak Sapi PO Kebumen EISSN: 2807-9361 Volume 01 Nomor 02 Desember 2021 $V(2), 77-85$.

Kustyorini, T. I. W., Krisnaningsih, A, T. N. \& Santitores, D. (2020). Frekuensi Penyiraman Larutan Urin Domba Terhadap Tinggi Tanaman, Jumlah Daun, dan produksi Segar Hidroponik Fodder Jagung (Zea mays). Jurnal Sains Peternakan, 8(1), 57-65.

Oyekunle, T., Okukenu, O., Dele, P., Oluwayemisi, A., Olajide, A., Ogunrombi, O., Jolaosho, A. \& Adekale, A. (2018). Proximate and Fiber Composition of Pennisetum purpureum Varieties in Stylosanthes guianensis Mixed Sward Fertilized with Two Manure Types. The Pacific Journal of Science and Technology, 19(2), 307-313.

Qohar, A. F., Hendarto, E. \& Munasik, M. (2020). Pertumbuhan Rumput Raja (Pennisetum purpureophoides) Defoliasi Kedua Akibat Pemupukan Kompos yang Diperkaya dengan Azolla microphylla. Prosiding Seminar Nasional Pembangunan Dan Pendidikan Vokasi Pertanian, 1(1), 1-9. https://doi.org/10.47687/snppvp.v1i1.120

Qohar, Adi Fathul, Hendarto, E., Hidayat, N., Bahrun, Harwanto \& Nuraeni, N. (2021). PENGARUH KOMBINASI DOSIS PEMUPUKAN KOMPOS ORGANIK DAN PENAMBAHAN AZOLLA TERHADAP PERTUMBUHAN RUMPUT RAJA. Jurnal Sains Peternakan Nusantara, 01(01), 1-12.

Qohar, A. F., Hidayat, N. \& Bahrun, B. (2019). Pengaruh Kombinasi Pupuk Kandang Dan NPK Terhadap Tinggi Tanaman Dan Jumlah Daun Rumput Odot (Pennisetum purpureum cv. Mott). Journal of Livestock and Animal Production, 2(1), 1-7.

Rayani, T. F., Resti, Y. \& Dewi, R. K. (2021). Kuantitas dan Kualitas Fodder Jagung, Padi dan Kacang Hijau dengan Waktu Panen yang Berbeda Menggunakan Smart hydroponic Fodder. Jurnal Ilmu Nutrisi Dan Teknologi Pakan, 19(2), $36-41$.

Roidah, I. S. (2014). Pemanfaatan Lahan Dengan Menggunakan Sistem Hidroponik. I(2), 43-50.

Saputro, A. L., Hamid, I. S., Prastiya, R. A. \& Purnama, M. T. E. (2018). Hidroponik Fodder Jagung sebagai Substitusi Hijauan Pakan Ternak Ditinjau dari Produktivitas Susu Kambing Sapera. Jurnal Medik Veteriner, 1(2), 48. https://doi.org/10.20473/jmv.vol1.iss2.2018.48-51

Sari, A., Liman \& Muhtarudin. (2016). Supporting of Agricultural by Product as Ruminant Feed in Pringsewu Dictrict. Jurnal Imiah Peternakan Terpadu, 4(2), 100-107.

Steel, R. G. D. and \& Torrie, J. H. (1994). Principle and Procedures of Statistics: A Biometrical Approach (Terjemahan: B. Soemantri (ed.)). PT. Gramedia 
Jurnal Sains Peternakan Nusantara Respon Palatabilitas Fodder Padi (Oryza Sativa) Hidroponik sebagai Pakan Ternak Sapi PO Kebumen EISSN: 2807-9361

Volume 01 Nomor 02 Desember 2021

Pustaka Utama.

Sudarma, I. M. A. (2018). Pengujian Konsistensi, Waktu Adaptasi, Palatabilitas dan Persentase Disintegrasi Ransum Blok Khusus Ternak Sapi Potong Antarpulau. Jurnal Sain Peternakan Indonesia, 13(3), 265-273. https://doi.org/10.31186/jspi.id.13.3.265-273

Suhardiyanto, H. (2011). Teknologi Hidroponik Untuk Budidaya Tanaman. IPB Press.

Suyitman. (2014). Produktivitas Rumput Raja (Pennisetum purpupoides) pada Pemotongan Pertama Menggunakan Beberapa Sistem Pertanian. Jurnal Peternakan Indonesia, 16(2), 119-127.

Suyitman, Jalaludin, S., Abudinar, N. M., Ifradi, N., Jamaran, M. P. \& Tanamasni. (2003). Agrostologi. Fakultas Peternakan Universitas Andalas.

Toe, P., Koten, B. B., Wea, R. \& Oematan, J. S. (2016). Pertumbuhan dan Produksi Rumput Setaria ( Setaria sphacelata ) Pada Berbagai Level Pemberian Pupuk Organik Cair Berbahan Feses Babi ( Growth And Forage Production Of Setaria Grass ( Setaria sphacelata ) at Different Level of Liquid Organic Fertilizer Made. Jurnal Ilmu Ternak, 16(2), 22-27.

Wahyono, T. \& Sadarman, S. (2020). Hydroponic Fodder: Alternatif Pakan Bernutrisi Di Masa Pandemi. Prosiding Seminar Teknologi Agribisnis Peternakan (Stap) Fakultas Peternakan Universitas Jenderal Soedirman, 558-566. 